\title{
Evaluation of Occlusal Incisal Tooth Wear and Its Influential Factors among Subjects Visiting a University Hospital in Pakistan
}

\author{
Rabia Ali ${ }^{1}$ \\ BDS \\ Farhan Raza Khan ${ }^{2}$ \\ BDS, MS, MCPS, FCPS
}

\begin{abstract}
:
INTRODUCTION: Tooth wear is a global problem that involves an irreversible, non-carious loss of dental hard tissues due to repetitive physical contacts or chemical dissolution. The objective of the study was to determine the frequency and influential factors of tooth wear among patients visiting AKUH dental clinic.

METHODOLOGY: Male and female patients in the age range of 20-70 years, presenting to Aga Khan University Hospital with symptomatic or asymptomatic tooth wear in their permanent dentition were included in the study. Clinical examination included tooth wear assessment of all incisors and first molars using Smith and Knight Tooth Wear Index. All findings were recorded into the examination proforma. Data was analyzed and influential factors (such as bruxism, lack of canine guidance and TMJ clicking etc.) of the tooth wear were determined by using Chi square test.

RESULTS: There were 114 subjects, 64 males and 50 females. The mild, moderate, moderately severe and severe tooth wear was observed in $23 \%, 36 \%, 28 \%$ and $12 \%$ of the subjects, respectively. Both genders had similar tooth wear scores. Among molars, occlusal surface was affected more with the wear compared to buccal/ lingual surface. Incisors exhibited more tooth wear on the incisal surface compared to labia or palatal/lingual surfaces.

CONCLUSIONS: Age more than 45 years and presence of TMJ clicking was found to be significantly associated with the tooth wear in incisors and molars. The occlusal and incisal surfaces among bruxers were affected more with tooth wear compared to their other tooth surfaces.
\end{abstract}

KEYWORDS: Tooth wear; tooth attrition; tooth abrasion; tooth erosion.

HOW TO CITE: Ali R, Khan FR. Evaluation of Occlusal Incisal Tooth Wear and Its Influential Factors among Subjects Visiting a University Hospital in Pakistan. J Pak Dent Assoc 2017; 26(1): 15-21

Received: 25 December 2016, Accepted: 12 March 2017

\section{INTRODUCTION}

$\mathrm{T}$ looth wear or tooth surface loss (TSL) is a global problem that involves an irreversible, non-carious loss of dental hard tissues due to repetitive physical contacts or chemical dissolution. ${ }^{1}$ It may occur in isolation or in combination with abrasion, attrition, erosion and abfraction. $^{2}$

Abrasion is the loss of tooth substance on nonmasticatory surfaces. ${ }^{3}$ It occurs due to the extrinsic physical

${ }^{1}$ Chief Resident, Operative Dentistry, Aga Khan University, Karachi

${ }^{2}$ Consultant \& Head, Operative Dentistry, Aga Khan University, Karachi

Corresponding author: "Dr. Farhan Raza Khan" < farhan.raza@aku.edu> forces like aggressive tooth brushing, use of dentifrice, nail or pencil biting etc. Attrition is the loss of tooth substance on masticatory/ occlusal and proximal surfaces. ${ }^{4}$ It is due to intrinsic physical forces e.g. by contact between occluding or proximal surfaces which also includes tooth wear caused by certain para-functional habits such as bruxism and clenching. Erosion is chemo-mechanical dissolution of tooth substance. ${ }^{5}$ It is due to acid which can be either from extrinsic or intrinsic sources for instance gastroesophageal reflux, a high intake of fizzy drinks, citrus fruit juices or fruit consumption. Abfraction is a type of non-carious cervical lesion (NCCL) characterized by cervical abrasive lesions thought to be caused by occlusal stresses. ${ }^{6}$

The prevalence of tooth wear is on the rise $;^{7}$ however, it is not established yet if this is due to the heightened 
awareness among patients and dental health care professionals or there is an actual inflation in the prevalence of tooth wear as a result of any changes in diet, life style or a combination of these factors. ${ }^{8}$ The incidence of tooth wear has been examined in 2009 UK Adult Dental Health Report. ${ }^{9}$ The results indicated that: a) $77 \%$ of dentate adults showed some tooth wear in their anterior teeth, b) $15 \%$ showed moderate wear and $2 \%$ had severe wear, c) men had higher incidence of tooth wear, d) moderate tooth wear increased from $11 \%$ in 1998 to $15 \%$ in 2009.

The etiology of tooth wear is known to be multifactorial, yielding various patterns of wear that commonly occur simultaneously complicating analysis and management. ${ }^{10} \mathrm{~A}$ study reported parafunctional activity $(69.7 \%)$, gastrointestinal problems $(60.5 \%)$, diet $(44.7 \%)$, foreign objects $(19.9 \%)$ and missing teeth $(9.2 \%)$ as some of the main etiological factors that lead to tooth wear. ${ }^{11}$

The diagnosis of tooth wear requires documenting the pathology first. This can be done by high quality study casts, photographs or dental records of the extent of the lesion using an internationally recognized tooth wear index such as one proposed by Smith and Knight. ${ }^{12}$ The objective of a tooth wear index (TWI) is to classify and record the severity of tooth wear in studies. Currently, a plethora of tooth wear indices exist that have been developed and used in the past 30 years. $^{13}$

Tooth wear is of concern to the dentists as this problem adversely affects esthetics and function. ${ }^{13}$ Except for a few studies, not much work has been done in Pakistan on this topic. A previous study at our center was conducted on noncarious cervical lesions (NCCLS) but it did not address the factors that have biological plausibility on the tooth wear. ${ }^{14}$

The present study is aimed to determine the frequency and the influential factors of molar incisor tooth wear in a sample of Pakistani population visiting a teaching institution.

\section{METHODOLOGY}

It was a cross-sectional study, conducted at the dental clinics, Aga Khan University Hospital from August 2014 to July 2015. Non-probability consecutive sampling technique was used to recruit patients belonging to either gender, in age range of 20-70 years, with symptomatic or asymptomatic tooth wear with all teeth of permanent dentition present. The patients who exhibited any active periodontal disease, carious teeth, trauma, developmental disorders, retained primary teeth, crown and bridge treatment on molars and incisors, bleaching procedures, orthodontic treatment and teeth with cracks / fracture were excluded from the study.
The sample size was calculated using a statistical calculator "Sample Size Determination in Health Studies, WHO". Cunha Cruz ${ }^{10}$ has reported the prevalence of tooth wear as $51 \%$. Keeping this population proportion with relative precision of 0.18 at confidence interval of 0.95 , the sample size requirement turned out to be 114 .

After obtaining the informed consent from the participating subjects, clinical examination was done on the dental chair using routine oral examination instruments i.e. a regular mouth mirror and an explorer probe. Tooth wear assessment of all incisors and first molar teeth was done using the Smith and Knight Index (Illustration I). All readings were recorded in the study proforma. The approval from the institutional ethics committee was obtained before the initiation of the study (ERC reference \# 3427-Sur-ERC-14).

\section{Data Analysis}

SPSS 20.0 was used for data analysis. Mean and SD were computed for the quantitative variables such as number of teeth and surfaces evaluated. Whereas, frequency distribution of the qualitative variables such as severity of tooth wear was determined. Although, the actual TWI data at subject level was ordinal in nature but mean tooth wear scores were derived for the purpose comparison between groups.

Chi- square was applied to determine the association between tooth wear and factors such as age, bruxism, TMJ clicking etc. Independent samples $\mathrm{T}$ test was applied to compare mean tooth wear scores between the genders, age groups (<45 vs. $>45$ years) and bruxers vs. non-bruxers. The level of significance was kept at 0.05 .

To control the selection bias, subjects were selected from all sub-specialties of the dental section. Confounders were controlled by stratifying the data into various sub-groups for the analysis. The groups were males and females, age <45 and $>45$ years, bruxers versus non-bruxers, subjects with TMJ clicking versus no TMJ clicking.

\section{RESULTS}

Two hundred and forty subjects attending the Aga Khan University hospital for their executive dental checkups were invited to take part in the study. Forty patients declined participation in the study. Sixty five were excluded for presence of crown bridge work in mouth. Fifteen were excluded on account of missing teeth and six were excluded because of history of orthodontics.

The final sample of 114 subjects comprised of 64 males and 50 females. The mean age in our study sample was $46.01 \pm 15.7$ years. Forty three percent of the study sample 
reported having gastroesophageal reflux disorder (GERD), however only $36 \%$ of these patients reported using Antacid drugs. The mild, moderate, moderately severe and severe tooth wear was observed in $23 \%, 36 \%, 28 \%$ and $12 \%$ of the subjects, respectively.

Table 1 of our study describes the oral hygiene and parafunction related factors. Most of the patients were brushing teeth on twice daily basis. Most common brush type was 'medium' and most common technique used was manual tooth brushing. Most commonly found parafunctional habit was bruxism.

Table 1. Distribution of Oral Hygiene regimen and parafunction related factors $(n=114)$.

\begin{tabular}{|c|c|c|c|}
\hline Variable & Category & Frequency & $\%$ \\
\hline \multirow{3}{*}{ Dental visits } & 6-12 months & 27 & 23.6 \\
\hline & Mora than 12 months & 51 & 44.7 \\
\hline & Never & 36 & 31.6 \\
\hline \multirow{4}{*}{$\begin{array}{c}\text { Frequency of } \\
\text { tooth } \\
\text { brushing }\end{array}$} & Less than once daily & 15 & 13.2 \\
\hline & Once daily & 33 & 28.9 \\
\hline & Twice daily & 56 & 49.1 \\
\hline & Three or more & 10 & 8.8 \\
\hline \multirow{3}{*}{$\begin{array}{c}\text { Tooth } \\
\text { brushing } \\
\text { technique }\end{array}$} & Upward \& downward & 37 & 32.5 \\
\hline & Forward \& backward & 65 & 57.0 \\
\hline & Bass technique & 12 & 10.5 \\
\hline \multirow{3}{*}{$\begin{array}{l}\text { Type of tooth } \\
\text { brush }\end{array}$} & Hard & 20 & 17.5 \\
\hline & Medium & 46 & 57.9 \\
\hline & Soft & 48 & 42.1 \\
\hline \multirow{2}{*}{$\begin{array}{l}\text { Method of } \\
\text { tooth } \\
\text { brushing }\end{array}$} & Manual & 87 & 78.1 \\
\hline & Electric & 25 & 21.9 \\
\hline \multirow{4}{*}{ Nail biting } & Never & 85 & 74.6 \\
\hline & Occasionally & 11 & 9.6 \\
\hline & Regularly & 0 & 0.0 \\
\hline & Not noticed & 18 & 15.8 \\
\hline \multirow{4}{*}{ Object biting } & Never & 90 & 78.9 \\
\hline & Occasionally & 5 & 4.4 \\
\hline & Regularly & 1 & 0.9 \\
\hline & Not noticed & 18 & 15.8 \\
\hline \multirow{4}{*}{ Bruxism } & Never & 17 & 14.9 \\
\hline & Occasionally & 21 & 18.4 \\
\hline & Regularly & 23 & 20.2 \\
\hline & Not noticed & 53 & 46.5 \\
\hline
\end{tabular}

Table 2. Dietary habits of the participants $(n=114)$.

\begin{tabular}{|c|c|c|c|}
\hline Consumption & Categories & Frequency & $\%$ \\
\hline \multirow{6}{*}{ Favorite drink } & Water & 18 & 15.8 \\
\hline & Carbonated & 25 & 21.9 \\
\hline & Milk & 2 & 1.8 \\
\hline & Herbal / Lemon tea & 13 & 11.4 \\
\hline & Tea & 45 & 39.5 \\
\hline & Coffee & 11 & 9.6 \\
\hline \multirow{5}{*}{ Citrus fruits } & Never & 13 & 11.4 \\
\hline & Less than once a week & 69 & 60.5 \\
\hline & At least once a week & 18 & 15.8 \\
\hline & On average once a day & 10 & 8.8 \\
\hline & More than once a day & 4 & 3.5 \\
\hline \multirow{5}{*}{$\begin{array}{c}\text { Citrus flavored } \\
\text { sweets }\end{array}$} & Never & 95 & 83.3 \\
\hline & Less than once a week & 8 & 7.0 \\
\hline & At least once a week & 2 & 1.8 \\
\hline & On average once a day & 5 & 4.4 \\
\hline & More than once a day & 4 & 3.5 \\
\hline \multirow{3}{*}{ Pan/ Chaliya * } & At least once a week & 15 & 13.2 \\
\hline & On average once a day & 23 & 20.2 \\
\hline & More than once a day & 32 & 28.1 \\
\hline \multirow{3}{*}{ Snuff Dipping } & At least once a week & 1 & 0.9 \\
\hline & On average once a day & 8 & 7.0 \\
\hline & More than once a day & 12 & 11.4 \\
\hline \multirow{2}{*}{ Smoking } & Less than 10 cigarettes/day & 7 & 6.2 \\
\hline & More than 10 cigarettes/day & 16 & 14.0 \\
\hline \multirow{2}{*}{$\begin{array}{l}\text { Smoking } \\
\text { duration }\end{array}$} & Less than 1 year & 5 & 4.4 \\
\hline & More than 1 year & 18 & 15.8 \\
\hline
\end{tabular}

*Refers to areca/ betel nut.

Table 2 shows the diet and tobacco intake related factors with 'Tea' as the most commonly used drink. Soft drinks were more common than sports drinks with predominant frequency of intake being less than once a week. The 
frequency of intake of pan/chaliya showed that most of the patients were consuming it for more than once daily. Most common intake frequency of tobacco/ snuff dipping was also more than once daily. Smoking 10 cigarettes per day with more than 1 year of smoking history was noted in some patients.

Table 3 describes the TMJ and occlusal findings. Patients reporting tenderness and clicking usually had involvement of both left and right sides. Some patients had a degree of mandibular deviation, with majority being on opening and towards the right side. Group function occlusal guidance was commonly found among the study sample.

Table 3. Extra-oral and intra-oral findings $(n=114)$.

\begin{tabular}{|c|c|c|c|}
\hline Variable & Category & Frequency & $\%$ \\
\hline \multirow{2}{*}{$\begin{array}{c}\text { TMJ } \\
\text { Tenderness }\end{array}$} & Yes & 30 & 26.3 \\
\hline & No & 84 & 73.7 \\
\hline \multirow{4}{*}{$\begin{array}{c}\text { TMJ } \\
\text { Tenderness } \\
\text { site }\end{array}$} & Left & 5 & 4.4 \\
\hline & Right & 2 & 1.8 \\
\hline & both & 23 & 20.2 \\
\hline & No & 84 & 73.7 \\
\hline \multirow{2}{*}{ TMJ Click } & Yes & 68 & 59.6 \\
\hline & No & 45 & 39.5 \\
\hline \multirow{4}{*}{ Clicking site } & Left & 2 & 1.8 \\
\hline & Right & 10 & 8.8 \\
\hline & Both & 56 & 49.1 \\
\hline & No & 46 & 40.4 \\
\hline \multirow{2}{*}{ Deviation } & Yes & 10 & 8.8 \\
\hline & No & 104 & 91.2 \\
\hline \multirow{2}{*}{ Deviation site } & To Left & 2 & 1.8 \\
\hline & To Right & 8 & 7.0 \\
\hline \multirow{2}{*}{$\begin{array}{c}\text { Deviation } \\
\text { point }\end{array}$} & On opening & 9 & 7.9 \\
\hline & On closing & 1 & 0.9 \\
\hline \multirow{2}{*}{ Jaw opening } & Less than $40 \mathrm{~mm}$ & 18 & 15.8 \\
\hline & More than $40 \mathrm{~mm}$ & 96 & 84.2 \\
\hline \multirow{2}{*}{ Right side } & Canine guidance & 46 & 40.4 \\
\hline & Group function & 68 & 59.6 \\
\hline \multirow{2}{*}{ Left side } & Canine guidance & 42 & 36.8 \\
\hline & Group function & 72 & 63.2 \\
\hline
\end{tabular}

Table 4 shows descriptive statistics on tooth wear assessment of the patients. Moderate wear (grade II) as shown in Smith and Knight Index was commonly observed in this sample. Among maxillary and mandibular molars, occlusal surface was affected more with the tooth wear compared to the buccal/ lingual surfaces. Both upper and lower Incisors exhibited more tooth wear on their incisal surfaces compared to labial or palatal/lingual surfaces.

Table 5 shows that there is no association between gender and over all tooth wear. Age (more than 45 years) was statistically associated with overall tooth wear. Although bruxers had more molars affected with tooth wear, however, bruxism was not found to be significantly associated with overall tooth wear. High tooth wear scores (grade III and above) were observed in subjects with TMJ clicking.

\section{DISCUSSION}

We had 114 patients with symptomatic or asymptomatic tooth wear assessed by using Smith and Knight Index. The age range in our study was from 20-70 years. There were majority of male patients in the study sample. The male predominance in tooth wear studies is a common observation. ${ }^{15,}{ }^{16}$ It may be because females are more conscious about their dental needs and probably pay frequent dental visits as a result, there are chances of an early detection of and hence likely to get appropriate intervention and preventive education against tooth wear. In addition, males have higher masticatory forces as compared to females thus are more prone to tooth wear than females.

The most common medical problem reported by the subjects in the present study was GERD. This factor holds important place in erosive tooth wear and is reported in other studies too. ${ }^{8,} 17$, Data on oral hygiene maintenance of the subjects showed that most of the patients reported using manual brushing technique (87\%) with medium bristle configuration. These findings are in agreement with study done by Oginni et al. ${ }^{15}$

Bruxism is considered a common parafunctional habit, either while sleeping or awake. ${ }^{18,19}$ Our study reports the same, in which $20.2 \%$ of the study sample had bruxism. However, there was no statistically significant association between tooth wear and bruxism. This result was similar for the type of tooth, the type of surface involved as well as for maximum over all wear score. Probable explanation for this is that we had a misclassification bias for bruxism. Parafunctional grinding or bruxism is often associated with tooth wear in the literature. ${ }^{11,} 20$ However, we failed to determine any such association. 
Table 4. Tooth wear findings $(n=114)$.

\begin{tabular}{|c|c|c|c|c|c|}
\hline \multirow{2}{*}{ Variable } & \multirow{2}{*}{ Category } & \multirow{2}{*}{ Count } & \multirow{2}{*}{$\%$} & \multicolumn{2}{|c|}{ Tooth wear score } \\
\hline & & & & Mean \pm SD & Range \\
\hline \multirow{8}{*}{ Most affected tooth } & Maxillary incisors & 10 & 8.8 & $0.91 \pm 0.57$ & $0-2.66$ \\
\hline & Maxillary molars & 3 & 2.6 & $1.02 \pm 0.69$ & $0-2.66$ \\
\hline & Mandibular Incisors & 6 & 5.3 & $0.88 \pm 0.57$ & $0-2.66$ \\
\hline & Mandibular Molars & 18 & 15.8 & $1.04 \pm 0.71$ & $0-3$ \\
\hline & Maxillary + Mandibular incisors & 23 & 20.2 & & \\
\hline & Maxillary + Mandibular molars & 47 & 41.2 & & \\
\hline & All teeth & 7 & 6.1 & & \\
\hline & Total & 114 & 100 & & \\
\hline \multirow{8}{*}{ Most affected surface } & Surface & Count & $\%$ & Median Score & Range \\
\hline & Buccal & 2 & 1.8 & 0 & $0-3$ \\
\hline & Palatal/ Lingual & 11 & 9.6 & 1 & $0-2$ \\
\hline & Occlusal & 38 & 33.3 & 2 & $0-4$ \\
\hline & Incisal & 34 & 29.8 & 2 & $0-4$ \\
\hline & Occlusal / incisal & 20 & 17.5 & & \\
\hline & Buccal+ occlusal/ incisal & 9 & 7.9 & & \\
\hline & Total & 114 & 100 & & \\
\hline \multirow{5}{*}{$\begin{array}{l}\text { Overall tooth wear scores } \\
\text { (patient level data) }\end{array}$} & Mild & 27 & 23.7 & & \\
\hline & Moderate & 41 & 36.0 & & \\
\hline & Moderately severe & 32 & 28.1 & & \\
\hline & Severe & 14 & 12.3 & & \\
\hline & Total & 114 & 100 & & \\
\hline
\end{tabular}

*Smith and Knight Index was used.

Table 5. Factors associated with tooth wear $(n=114)$.

\begin{tabular}{|c|c|c|}
\hline Factors & Categories & P-value \\
\hline \multirow{2}{*}{ Age } & $<45$ year & \multirow{2}{*}{$<0.001$} \\
\hline & $>45$ year & \\
\hline \multirow{2}{*}{ Gender } & Male & \multirow{2}{*}{0.25} \\
\hline & Female & \\
\hline \multirow{2}{*}{ TMJ clicking } & Yes & \multirow{2}{*}{$<0.001$} \\
\hline & No & \\
\hline \multirow{2}{*}{ Bruxism } & Yes & \multirow{2}{*}{0.26} \\
\hline & No & \\
\hline
\end{tabular}

A unique feature in our study sample was the consumption of pan/ chaliya. As shown in the results (Table 2) nearly $28 \%$ of the population was consuming it more than once daily $(11.4 \%)$. Most of the studies have studied the effect of betel nut or pan/ chaliya on oral mucosa. ${ }^{21}$ However, their effect on tooth wear is not frequently reported. ${ }^{5}$

Most of our subjects had group function occlusal scheme on lateral excursion. With advancing tooth wear, canine guided occlusion is reduced to group function. In this study, the anterior teeth showed greater wear on the incisal surfaces. Most common teeth affected by tooth wear were molars in both the maxillary or mandibular dentition. The most affected surface was occlusal surfaces. Majority of the study subjects $41(36 \%)$ belonged to moderate tooth wear 


\begin{tabular}{|c|c|c|}
\hline Score & Surface & Criteria \\
\hline 0 & $\begin{array}{l}\mathrm{B} / \mathrm{L} / \mathrm{O} / \mathrm{I} \\
\mathrm{C}\end{array}$ & $\begin{array}{l}\text { No loss of enamel surface characteristics. } \\
\text { No loss of contour. }\end{array}$ \\
\hline 1 & $\begin{array}{l}\mathrm{B} / \mathrm{L} / \mathrm{O} / \mathrm{I} \\
\mathrm{C}\end{array}$ & $\begin{array}{l}\text { Loos of enamel surface characteristics. } \\
\text { Minimal loss of contour. }\end{array}$ \\
\hline 2 & $\begin{array}{l}\mathrm{B} / \mathrm{L} / \mathrm{O} \\
\mathrm{I} \\
\mathrm{C}\end{array}$ & $\begin{array}{l}\text { Loss of enamel exposing dentine for less than one third of surface. } \\
\text { Loss of enamel just exposing dentine. } \\
\text { Defect less than } 1 \mathrm{~mm} \text { deep. }\end{array}$ \\
\hline 3 & $\begin{array}{l}\mathrm{B} / \mathrm{L} / \mathrm{O} \\
\mathrm{I} \\
\mathrm{C}\end{array}$ & $\begin{array}{l}\text { Loss of enamel exposing dentine for more than one third of surface. } \\
\text { Loss of enamel and substantial loss of dentine. } \\
\text { Defect less than 1-2 mm deep. }\end{array}$ \\
\hline 4 & $\begin{array}{l}\mathrm{B} / \mathrm{L} / \mathrm{O} \\
\mathrm{I} \\
\mathrm{C}\end{array}$ & $\begin{array}{l}\text { Complete enamel loss - pulp exposure - secondary dentin exposure. } \\
\text { Pulp exposure or exposure of secondary dentine. } \\
\text { Defect more than } 2 \mathrm{~mm} \text { deep - pulp exposure - secondary dentine exposure. }\end{array}$ \\
\hline
\end{tabular}

B: buccal; L: lingual; O: occlusal; I: incisal; C: cervical.

Fig. (1). Smith and Knight tooth wear index 12.

category (Table 4). The median tooth wear score of 2 indicates loss of enamel and a substantial loss of dentin on the incisal and occlusal surfaces of these teeth. The reasons for this higher degree of wear observed may be because of thin enamel at incisal and occlusal surfaces and their active role in both masticatory and excursive jaw movements during function as well as parafunction. These results were consistent with the findings of Liu et al. ${ }^{22}$

We found a statistically significant association between age and presence of tooth wear $(p$-value $=0.02)$. Our results show that subjects with age of more than 45 years had significant tooth wear as compared to those belonging to less than 45 years of age group. This is a fairly common finding and is consistently reported by other studies as well. ${ }^{15,22-25}$ The main reason for this observation is probably that the elderly are living longer and retaining their teeth as well. There has been a potential increase in dental hygiene awareness among the masses, people are more conscious of their dental needs. Therefore, longer retention of natural dentition leads to more wear of the occluding facets, hence leading to a common observation that elderly patients have worn down dentition than the younger subjects. ${ }^{25}$

The association of TMJ clicking with tooth wear was a major finding in our study as it was statistically significant ( $\mathrm{p}$-value $=0.04)$. In addition to that, higher wear scores were also associated with subjects having TMJ clicking. Our finding is similar to the study done by Liu et al. ${ }^{22}$ The prevalence of TMJ clicking among tooth wear patients was $36.6 \%$ in that study whereas in the present study, it is nearly $60 \%$. There was involvement of incisors and molars. This finding is also similar to our study in which the mean overall wear score was more for patients with TMJ clicking. Clicking was commonly found in patients in whom there was differential wear of occlusal surfaces. This is in contrast with Al-Zarea ${ }^{26}$ who reported a lack of association between tooth wear and TMJ clicking.

The limitations of the present study include recording of tooth wear on incisors and molars only. The premolars and canines were not included in the evaluation and analysis. In addition to that, there was an important bias in the sample selection as only the subjects with tooth wear were included in the study. Thus, the actual prevalence of tooth wear could not be ascertained. Moreover, no comparison could be made for tooth wear versus no tooth wear subjects for factors related to the tooth wear. However, a similar strategy was adopted by Liu et al. who investigated incisal/occlusal tooth wear prevalence and the related factors among elderly population in northwest China. ${ }^{22}$ Hence, recruiting a biased sample of tooth wear subjects only is justified. Another limitation was transforming the ordinal tooth wear data into continuous data to derive mean tooth wear scores. It was done for comparison of scores between the sub-groups. This approach too is evidence based and reported in the Liu et al. study. ${ }^{22}$ However, the median scores and range of tooth wear were also reported in the present study.

Tooth wear is a condition being frequently encountered by general dental practitioners. It is vital to accurately assess and diagnose a patient presenting with tooth wear. The majority of such cases can be successfully treated by simple preventive measures, dietary modifications, long term monitoring and maintenance. 


\section{CONFLICT OF INTERESTS:}

None to disclose

\section{ACKNOWLEDGEMENTS}

Declared none.

\section{AUTHORS' CONTRIBUTION}

RA: conceived the study, carried out data collection and wrote the primary draft.

FRK: supervised the project, did the data analysis, interpretation and critically reviewed the manuscript.

\section{REFERENCES}

1. Burke FM, McKenna G. Toothwear and the older patient. Dent Update. 2011; 38(3): 165-8.

2. Saerah N, Ismail N, Naing L, Ismail A. Prevalence of tooth wear among 16-year-old secondary school children in Kota Bharu Kelantan. Arch Orofacial Sci. 2006; 1: 21-8.

3. Milosevic A. Toothwear: aetiology and presentation. Dent Update. 1998; 25(1): 6-11.

4. Kelleher M, Bishop K. The aetiology and clinical appearance of tooth wear. Eur J Prosthodont Restor Dent. 1997; 5(4): 157-60.

5. Imfeld T. Dental erosion. Definition, classification and links. Eur J Oral Sci. 1996; 104(2): 151-5.

6. Barbour M, Rees G. The role of erosion, abrasion and attrition in tooth wear. J Clin Dent. 2005; 17(4): 88-93.

7. Kreulen CM, Van't Spijker A, Rodriguez JM, Bronkhorst EM, Creugers NH, Bartlett DW. Systematic reviews of the prevalence of tooth wear in children and adolescents. Caries Res. 2010; 44(2): 151-9.

8. Ganss C, Young A, Lussi A. Tooth wear and erosion: methodological issues in epidemiological and public health research and the future research agenda. Community Dent Health. 2011; 28(3): 191-5.

9. Steele J, Treasure E, O'sullivan I, Morris J, Murray J. Adult dental health survey 2009: Transformations in British oral health 1968-2009. Br Dent J. 2012; 213(10): 523-7.

10. Cunha - Cruz J, Pashova H, Packard J, Zhou L, Hilton TJ. Tooth wear: prevalence and associated factors in general practice patients. Community Dent Oral Epidemiol. 2010; 38(3): 228-34.
11. Al-Omiri MK, Lamey PJ, Clifford T. Impact of tooth wear on daily living. Int J Prosthodont. 2006; 19(6): 601-5.

12. Smith BG, Knight JK. An index for measuring the wear of teeth. Br Dent J. 1984; 156: 435-8.

13. Lopez-Frias FJ, Castellanos-Cosano L, Martin-Gonzalez J, Llamas-Carreras JM, Segura-Egea JJ. Clinical measurement of tooth wear: tooth wear indices. J Clin Exp Dent. 2012; 4(1): e48-e53.

14. Ahmed H, Rahman M. Factors associated with noncarious cervical lesions (NCCLs) in teeth. J Coll Physicians Surg Pak. 2009; 19(5): 279-82.

15. Oginni O, Olusile AO. The prevalence, aetiology and clinical appearance of tooth wear: the Nigerian experience. Int Dent J. 2002; 52(4): 268-72.

16. Cunha - Cruz J, Pashova H, Packard J, Zhou L, Hilton TJ. Tooth wear: prevalence and associated factors in general practice patients. Community Dent Oral Epidemiol. 2010; 38(3): 228-34.

17. Bartlett DW, Evans DF, Smith BG. The relationship between gastro-oesophageal reflux disease and dental erosion. J Oral Rehabil. 1996; 23(5): 289-97.

18. Bartlett D, Fares J, Shirodaria S, Chiu K, Ahmad N, Sherriff $M$. The association of tooth wear, diet and dietary habits in adults aged 18-30 years old. J Dent. 2011;39(12): 811-6.

19. Mengatto CM, Coelho-de-Souza FH, de Souza Junior OB. Sleep bruxism: challenges and restorative solutions. Clin Cosmet Investig Dent. 2016; 8: 71-7.

20. Machado NA, Fonseca RB, Branco CA, Barbosa GA, Fernandes Neto AJ, Soares CJ. Dental wear caused by association between bruxism and gastroesophageal reflux disease: a rehabilitation report. J Appl Oral Sci. 2007; 15(4): 327-33.

21. Trivedy C, Craig G, Warnakulasuriya S. The oral health consequences of chewing areca nut. Addict Biol. 2002; 7(1): 115-25.

22. Liu B, Zhang M, Chen Y, Yao Y. Tooth wear in aging people: an investigation of the prevalence and the influential factors of incisal/occlusal tooth wear in northwest China. BMC Oral Health. 2014; 14: 65.

23. Poynter ME, Wright PS. Tooth wear and some factors influencing its severity. Restorative Dent. 1990; 6(4): 811.

24. Smith BG. Some facets of tooth wear. Ann R Australas Coll Dent Surg. 1991; 11: 37-51.

25. Van't Spijker A, Rodriguez JM, Kreulen CM, Bronkhorst EM, Bartlett DW, Creugers NH. Prevalence of tooth wear in adults. Int J Prosthodont. 22(1): 35-42.

26. Al-Zarea BK. Tooth surface loss and associated risk factors in northern Saudi Arabia. ISRN Dent. 2012; 2012: 161565 . 